\title{
A usage-based investigation of Afrikaans-speaking children's holophrases and communicative intentions
}

\author{
Nina Brink \\ Department of Afrikaans and Dutch, School of Languages, North-West University, Potchefstroom Campus \\ E-mail: Nina.Brink@nwu.ac.za
}

\begin{abstract}
Children of all languages use their first lexical items to express a variety of meanings or communicative intentions. The phase during which young children start to use their first lexical items is commonly characterised from a usage-based approach as a holophrastic stage because these lexical items, although just a single linguistic unit, are often used to fulfil more complex communicative intentions. The meaning of the lexical item is therefore mostly derived from the communicative context in which the utterance takes place. A holophrase is defined as one linguistic symbol that functions as a whole utterance and expresses more than the conventional meaning of that symbol. Studies on the communicative functions of children's holophrases do exist, but this phenomenon has not yet been studied in Afrikaans first language acquisition. Tomasello (2003: 37) provides a list of what young children from around the world normally do with their language (i.e. intentions typically expressed), and this study investigates to what extent these communicative intentions can also be applied to novel usage-based data of 20 Afrikaans-speaking children's first lexical items. This study reveals that the communicative intentions as expressed by Tomasello also describe the Afrikaans data set although some of the descriptions of the categories are expanded to include a larger variety of samples from the Afrikaans data. Furthermore, two other types of communicative intentions are identified in the Afrikaans data, namely to express an emotion/feeling, and to respond to a conversation partner by means of imitation. Other studies done on children's expression of emotions and imitations of words provide further evidence that children also use their language to communicate these intentions. As such, this article contributes to the body of literature on Afrikaans first language acquisition as an under-researched field.
\end{abstract}

Keywords: Afrikaans first language acquisition; communicative intention; holophrase; usagebased approach 


\section{Introduction ${ }^{1}$}

Children often use their first lexical items to express a variety of communicative intentions, and this phenomenon is mainly investigated from a usage-based approach in the literature. The phase during which children begin to use their first lexical items is commonly characterised within the usage-based approach as a holophrastic phase (Cattell 2000: 6). According to Tomasello (2000: 65), a child wants to understand what an adult is trying to communicate to $\mathrm{him} / \mathrm{her}$, but when the child wants to communicate in turn, s/he often only succeeds in (re)producing one linguistic element of the adult's whole utterance. This one linguistic element then has to fulfil the function of a whole utterance. A holophrase can therefore be defined as one linguistic symbol that functions as a whole utterance and expresses more than the conventional meaning of that symbol (Barrett 1982: 48). McNeill (1970: 20) suggests that "“holophrastic speech' refers to the possibility that the single-word utterances of young children express complex ideas, that ball means not simply a spherical object of appropriate size but that a child wants such an object, for example, or that he believes he has created such an object, or that someone is expected to look at such an object".

The phenomenon of holophrases, or the meaning and function of one-word utterances, has been investigated in international literature or discussed as part of larger themes within child language research (see Barrett 1982, 1985; Bates 1976; Cattell 2000; Clark 2001, 2003; Dore 1975; Greenfield and Smith 1976; Halliday 1975; Lachlan Mackenzie 1998; MacWhinney 1975, 1982; McNeill 1970; Small 1990; Tomasello 2000, 2003; Tomasello and Bates 2001). More recent literature in this field has been grounded in communication disorders (see Gândara and Befi-Lopes 2010, Hann et al. 2017, McDaniel et al. 2018, Sandbank et al. 2017, Windfuhr et al. 2002) and the influence of socio-economic status, race/ethnicity, or gender among preschoolers on their communicative function use (Fannin et al. 2018). However, as argued in Brink and Breed (2017), the field of Afrikaans first language acquisition of typicallydeveloping children is still under-researched.

Tomasello (2003: 37) states that young children of linguistic communities from around the world combine basic speech act motives with their salient scenes of experience to "do" certain things with their earliest productive language. These communicative intentions, as posited by Tomasello (2003: 37), are the following:

- to request or indicate the existence of objects (for example, by naming them with a requesting or neutral intonation);

- to request or describe the recurrence of objects or events (more, again, another);

- to request or describe dynamic events involving objects (as described by up, down, on, off, in, out, open, close);

- to request or describe the actions of people (eat, kick, ride, draw);

- to comment on the location of objects and people (here, outside);

- to ask some basic questions (what's that?, where go?);

- to attribute a property to an object (pretty, wet); and

- to use performatives to mark specific social events and situations (hi, bye, thank you, no).

\footnotetext{
${ }^{1}$ I would like to thank the anonymous reviewers for their extremely valuable suggestions on how to improve an earlier version of this manuscript. I would also like to thank my colleagues, Adri Breed, Gerhard van Huyssteen, Karien van den Berg, and Lande Botha, for critically reading an earlier version of this manuscript, and for their advice and discussions with me about the content thereof.
} 
Tomasello provides an overview of the commonalities of what children from various linguistic communities generally want to convey with their language. The research question guiding this current study, however, is to what extent can these usage-based categories of communicative intentions aptly describe Afrikaans-speaking children's holophrases? Therefore, how do these categories compare to Afrikaans language acquisition data? This article will contribute to the literature by describing usage-based Afrikaans data and determining how the Afrikaans data set compares to communicative intentions children from around the world generally have with their first lexical items.

In order to address the research question, this paper briefly reviews literature on first language acquisition as explored from a usage-based approach (section 2). This is followed by a discussion in section 3 of the holophrastic structure of first lexical items by referring to the form and functions of this early language usage. The method of investigation is then discussed in section 4 by providing an exposition of the research group, respondents and methods of data gathering. Lastly, the results and conclusion of the study are discussed in sections 5, 6, and 7.

\section{First language acquisition from a usage-based approach}

When studying the communicative intentions that children have with their first lexical items, the usage-based approach is relevant due to a number of its premises. This approach presupposes that children learn linguistic expressions from the language used in their environment and then use certain general cognitive and social-cognitive abilities such as categorisation (pattern-finding), schematisation, intention-reading (within a joint attentional frame), entrenchment, and generalisation to combine and structure these learnt expressions in a creative manner (Behrens 2009, Tomasello 2001, Tomasello and Bates 2001, Tomasello 2003). Cognitive development is important for the process of learning new words seeing that a person cannot talk about something $\mathrm{s} /$ he does not yet understand and has not yet conceptualised.

Tomasello and Bates (2001: 5-6) state that "children must acquire words by extracting their forms from complex utterances and their meanings from complex social-communicative situations; and to produce them they must integrate them into their larger communicative situations". The authors acknowledge that the word-learning process is part of a complex set of processes through which children learn to associate the intended meaning with a linguistic form. By means of entrenchment, abstraction, and generalisation, schemas that categorise experiences are formed (Behrens 2009: 386). A schema can be defined as a semantic, phonological or symbolic structure and, through the process of generalisation, new structures are based on previous experiences (Behrens 2009: 387). These processes of entrenchment, categorisation, schema formation, and generalisation then connect to the term "emergence" which refers to the idea that novel and more complex structures can emerge from more basic facts. The usage-based approach is therefore based on a bottom-up approach where the more general emerges from the more specific.

Ambridge and Lieven (2015: 478-479) also emphasise that children only gradually abstract across holophrases and lexical schemas to "arrive at adult-like fully abstract constructions" and that the "generalizations that underlie linguistic competence emerge from the analysis of linguistic units stored in memory (initially, rote-learned holophrases), rather than being innately specified". They further mention that children's language acquisition is emergent from their use of language as a social tool. The way in which Ambridge and Lieven (2015: 479) describe how abstract schemas are formed summarises this notion: 
Children start out with holophrases which develop via a process of abstraction, first into lexical schemas, and finally into adult-like abstract constructions. Importantly, this process, whilst protracted and gradual, begins as soon as children have, in principle, two stored exemplars across which to abstract.

The notion of intention-reading within a joint attentional frame is also important for studying the communicative intentions children have with their holophrases. Intention-reading refers to aspects such as: (i) the child's ability to focus his/her attention together with other persons on a certain object or event, (ii) the child's ability to follow the attention and referral of other persons to objects or events that are not part of the immediate interaction, (iii) the child's ability to focus other persons' attention to a certain object by pointing or using other non-linguistic gestures, and (iv) the child's ability to culturally (imitatively) learn the intentional actions of other people, including their communicative intentions that underlie communication (Tomasello 2003: 3). Within the joint attentional frame, children can focus on the same situation or object on which their conversation partners are concentrating, as well as understand communicative intentions of others; children therefore begin to grasp that language can be used to manipulate the state of others (Clark 2015: 332, Turner 2015: 94). These skills start to develop at about the age of 0;9 to 1;0 when children start using their first lexical items (Tomasello 2003: 3).

Furthermore, another tenet of the usage-based approach as discussed by Kemmer and Barlow (2000: xi), especially of interest when studying children's communicative intentions, is the focus on the role that learning and experience play in the language acquisition process. Instances where language is produced and understood are of central importance in the structuring of the linguistic system from a usage-based approach, and thus also when this system is still forming. The grammatical structures a child learns are systematically constructed through specific experiences with language. A premise that corresponds with this is that real language data are important in the construction and description of theory (Kemmer and Barlow 2000: xv). This is why it is important to study first language acquisition by means of real and original language data, and also to consider the context of use when making assumptions about the communicative intentions the child wants to fulfil with his/her lexical items.

\section{Holophrastic structure of first lexical items}

A child just beginning to learn a language still has a very restricted vocabulary, and therefore has to try and achieve as much as possible with the linguistic repertoire s/he has available at that stage. This situation leads to children's first lexical items having a holophrastic structure, i.e. one lexical item functioning as a whole utterance and fulfilling more than one function depending on the context of use. An example of a holophrase, as given by Tomasello (2000: 65), is that of "ball?" which can mean "where is the ball?" or "ball" which can mean "give me the ball".

Following a usage-based perspective, children initially talk about various experiences in various ways, and these first lexical items provide a framework for language learning and development. Furthermore, their utterances often reflect salient components of fully formed utterances that adults use in those situations. According to Tomasello (2003: 39), "[f]unctionally speaking, children's early one-unit utterances are entire semantic-pragmatic packages - holophrastic expressions - that express a single relatively coherent, yet undifferentiated, communicative intention". 
Parents often depend on cues such as intonation or gesture to derive the meaning of the holophrase. Cole and Cole (2001: 306) emphasise that some researchers view the single word in conjunction with gestures and facial expressions as the equivalent of the whole sentence. In this view, the single word is "one element in a complex of communication that includes nonverbal actions" (Cole and Cole 2001: 306). This corresponds with the usage-based notion of intention-reading within a joint attentional frame, as it is necessary for the parent to be directly involved in the communication situation to be able to read the intention that the child has with the use of only one lexical item.

The child's choice of which part of the adult's utterance they will use as initial holophrase is an important issue for later language development. According to Tomasello (2003: 37-38), the answer probably lies in the specific language being learnt and the type of discourse in which the interaction with the adult takes place, as well as the perceptual salience of specific words and phrases in the adult's language use. He further explains that children learning English will probably initially rely on relational words such as more, gone, up, down, on, and off, probably because these words are salient in adult language use (Tomasello 2003: 38):

Many of these words are verb particles in adult English, and so the child at some point must learn to talk about the same events with phrasal verbs such as pick up, get down, put on, and take off. In Korean and Mandarin Chinese, in contrast, children learn fully adult verbs from the onset of language development because these verbs are more salient in adult speech to them.

Furthermore, Tomasello (2003: 38) argues that children in all languages also use the term for an object to express certain events or actions, for example, "bike!" may be used as a request to ride a bicycle, or "birdie!" to refer to a bird flying by. In these instances, these children still have to learn to linguistically express the particular activity such as "ride bike!" or "look birdie".

The question of which word the child will choose as the holophrase also relates to children's inclination to learn certain words or parts of speech first. However, the conventional part of speech into which a word can be categorised does not always convey what the child's communicative intention with the word is (as can be seen in the examples of "bike" and "birdie" above). Therefore, further investigation into the context of use is necessary. Tomasello (2003: 45) also emphasises that "virtually no one believes that adult part-of-speech categories are relevant to children just beginning to learn language". Tomasello (2003: 45) therefore mentions categories that could seem more "relevant" to children but without proposing that these categories are in any way real for them:

- General nominals: apple, shoe

- Specific nominals: Sarah, Mommy

- Action words: throw, dance

- Personal-social words: bye-bye, thank you

- Modifiers: cold, wet

- Functors: of, and

According to Clark (2001: 379), the first 50 words of children from around the world tend to be similar in content, but "as children learn more about the specific language they are acquiring, the courses they follow diverge more and more". There are thus certain types of words which 
children in general learn first, as can be seen in Crystal's (2005) study on the semantic categories into which early child language can be divided. These categories are: human, action, food, body part, clothing, animal, vehicle, toys and games, domestic object, location, descriptive words, and situational words. The early similarities between children's language use are ascribed to children's comprehension of conceptual categories such as agent, action, place, and so forth, and this provides the basis for meanings that can be mapped onto certain linguistic forms (Clark 2001: 379). Tomasello (2003: 45) remarks that it appears that nouns are generally learnt earlier than verbs or other parts of speech. This does not however mean that nouns are only used for a specific referent but also can be used to fulfil a variety of functions.

The establishment of common ground, as discussed by Clark (2015), is an important notion within the usage-based approach and also links to the prerequisite of joint attention. Without common ground and joint attention between the speaker, in this case the child, and the conversation partner, in this case mainly the parent, the communication is unlikely to succeed. Clark (2015: 328) describes common ground as information being known and recognised by both the speaker and the addressee. This information - usually aspects such as a physical entity present in the joint attentional frame, the family setting, particular caregivers, daily routines, etc. - contributes to a store of knowledge about perceptual and conceptual categories that children employ when conveying their message, by means of a holophrase, to the other person involved in the interaction (Clark 2015: 332-333). The establishing of common ground, and the children's use of holophrases for interaction purposes, also connects to the interactionist theory of language acquisition in which the interaction between speaker and addressee plays a central role in the learning of language (Miller et al. 2014: 246).

Within the usage-based approach, the essence of a holophrase is the communicative function which the child's utterance needs to fulfil. According to Tomasello (2003: 36), these early communicative functions of children's one-word utterances are an integral part of the child's reality, and these functions (e.g. imperative or interrogative) can initially not be as distinguishable from the more referential aspects of the utterance. In this light, children's early one-word utterances are seen as holophrases that represent holistic, undifferentiated communicative intentions, mostly the same communicative intentions as the adult's "complete" utterances.

The same lexical item can be used in various contexts with different emphasis and intonation, and this makes it possible to distinguish various meanings for the same lexical item, as explained by Cattell (2000: 6) below:

It's been shown that adults listening to babies' one-word utterances have a high level of agreement as to whether they'd classify particular examples as declarative, interrogative or emphatic utterances, based on what they themselves would mean if they used the particular intonation contour. For example, "car" said with a rising intonation contour might mean "Is this a car?", and with a falling contour might mean "This is a car". That might suggest that the different utterances of this single word are being used for fuller meanings.

Tomasello (2003: 37) notes that, regardless of the language being spoken, children usually talk about similar, salient experiences, such as "the existence-nonexistence-recurrence of people and objects, the exchange-possession of objects, the movement-location of people and objects, various states of objects, and the physical and mental activities of people". 
According to the usage-based approach, children's one-word utterances can be differentiated and reanalysed as the child's use of language develops (Behrens 2009: 396). The use of a holophrase therefore does not imply that the child already possesses a complete linguistic structure but rather that $\mathrm{s} /$ he is observing language and is busy building his/her linguistic structure, as Tomasello (2000: 66) elaborates:

And so what the holophrastic child needs to do to become a syntactically competent language user is to be able to move in both directions - from part to whole and from whole to part. She must be able either to "break down" or to "fill out" her holophrases so that she can express her communicative intentions in the more linguistically articulated way of adult speakers. Learning how to do this depends on the child's ability to comprehend not only the adult utterance as a whole, but also the functional role being played by the different linguistic elements in that whole. This is the beginnings of grammar.

A child then, when producing a holophrase, has allocated a certain function or intention of a whole utterance to a single linguistic unit of that utterance (or lexical item), and by expanding the utterance with other linguistic units, it will eventually become more like the conventionalised adult utterance (Tomasello 2003: 40). Adult feedback is an important aspect of mastering language through usage as "children learn the conventions of their language in part because adults consistently check up on children's intended meanings by reformulating in conventional terms what they think the child meant to convey" (Clark 2015: 337).

\section{Method of investigation}

This section describes the method of investigation to collect data in order to answer the research question of this paper, namely to what extent the usage-based categories of communicative intentions, as mentioned by Tomasello (2003: 37), can also aptly describe Afrikaans-speaking children's holophrases. This study is done from a usage-based approach and therefore novel usage-based data are of particular importance in answering this question. A description of the participants and procedure as well as the framework and criteria used for the categorisation of the data are presented in the following subsections.

\subsection{Research group and respondents}

The research group of this study consisted of 20 children between the ages of $0 ; 6$ and $2 ; 0^{2}$ with Afrikaans as their mother tongue. Thirteen of the children were female and seven were male. Pseudonyms were allocated to the children to protect their privacy.

The children were the research group, but the mothers fulfilled the role of respondents and observers, and contact was only made with them. Parents are, in most cases, their children's closest and most constant observers. According to Pan (2012: 103), parents are generally considered as accurate reporters of their children's current behaviour and achievements. Peccei (2006: 72) also notes that naturalistic data collection, where the child's spontaneous language use is observed in his/her comfortable and natural environment, has many advantages. However, the

\footnotetext{
${ }^{2}$ These data have also been analysed for other studies on Afrikaans first language acquisition as this article forms part of a larger research project. This data set is available as an open-access resource on the database of the South African Centre for Digital Language Resources (SADiLaR).
} 
author also proposes that the researcher should not be present unless it is absolutely necessary, as this can make the child and parent uncomfortable and therefore influence the data.

When parents have to report on their child's lexical items, they do it from a wide database of daily interaction with the child. The parental report therefore has its advantages when it comes to assessing lexical items that children do not use that often and unknown observers may not hear in the limited time in which they observe (Pan 2012: 104). In most cases, parents have a better understanding of their child's utterance in a certain context than an unknown observer, as Pan (2012: 104) elaborates: "Furthermore, parents tend to be familiar with their child's articulation patterns, and thus are likely to report words deemed unintelligible by unfamiliar assessors or transcribers." It is because of these reasons that the mothers were the respondents of this study. The aim of the study was to capture the contextual utterance of lexical items in the child's natural and spontaneous environment in order to accurately determine the communicative intention of that utterance.

\subsection{Data collection and control}

Data were collected in the form of diary entries which the respondents completed on their children's language use for a period of five months (December 2014 to the end of April 2015). An electronic diary entry template in Microsoft Word was e-mailed to the respondents at the beginning of the period of investigation. This diary template required the respondents to provide information on features such as the lexical item used, at least three examples of contexts of use, the possible meaning of the lexical item (as derived by the parent), and the age at which the lexical item was used for the first time.

Additional resources were also sent to the respondents, namely an information document with more details about the study, and a short video that explained what should be filled in under each column of the diary entry template. After one month of data documentation, the respondents sent their first version of the diary entries to the researcher, and certain recommendations were made on how to improve the entries so that the data could be suitable for the aim of the study, e.g. when a respondent only provided one context of use for an utterance, it was suggested that she provide at least three contexts so that the researcher could have a broader scope of contexts to analyse.

In the final month of the period of investigation, a questionnaire was sent to the respondents in which certain contextual information on the child's environment was requested. This questionnaire did not form part of the data set but was used to (i) clear up possible uncertainties about the context in which certain lexical items were used, (ii) prompt the respondent to remember other lexical items that were not initially included in the diary entries, and (iii) elucidate the data set, namely the diary entries, as best as possible. This questionnaire was therefore used as a control measure and for the sake of triangulation of the data.

\subsection{Coding and organising the data}

The data were transferred from the diary entries the respondents supplied (either in Microsoft Word or PDF format) to an Excel spreadsheet, and then consolidated in one Excel spreadsheet. The columns used in Excel were the following: (i) Child, (ii) Lexical item, (iii) Contexts of use, and (iv) The communicative intention. As previously mentioned, the respondents had to provide three or more contexts of use for each lexical item, and the same lexical item could naturally 
be used for more than one communicative intention and in more than one utterance. In this current study, the focus is on the linguistic token and not specifically on the intonation and gesture that accompanied this token within the complex communication process. It is, however, assumed that the parent relied on certain cues, such as nonverbal actions, to derive a meaning. This also corresponds to Cole and Cole (2001: 306) who state that adults interpret an utterance based on information from the context in which the child speaks and what accompanies that utterance. In some cases, explicit information on intonation and/or gesture was provided by the respondent in the description of the context and was then factored into the analysis.

The children made a total of 1438 utterances in various contexts. A total of 67 of these utterances were coded as "unusable or not relevant" on the basis of one or more of the following reasons: (i) When the respondent was uncertain about the meaning or function of the particular lexical item; (ii) When a lexical item was not used in a specific, distinguishable context; (iii) When the lexical item was not established or identifiable; (iv) When too little information was provided by the respondent to be able to come to a concrete conclusion about the meaning or intention of that utterance; and (v) When the utterance could not be classified as a holophrase. Table 1 below contains a summary of the age of each child at the onset of data collection, the initial number of utterances per child, the number of utterances per child coded as "unusable", the total utterances that were therefore analysed for the study, and the percentage of the total number of utterances per child.

Table 1: Summary of number of utterances per child analysed for the study

\begin{tabular}{|l|c|c|c|c|c|}
\hline Child & $\begin{array}{c}\text { Age of child } \\
\text { at onset of } \\
\text { data } \\
\text { collection }\end{array}$ & $\begin{array}{c}\text { Number of } \\
\text { utterances }\end{array}$ & $\begin{array}{c}\text { Number of } \\
\text { utterances } \\
\text { coded as } \\
\text { unusable }\end{array}$ & $\begin{array}{c}\text { Total } \\
\text { utterances } \\
\text { analysed }\end{array}$ & $\begin{array}{c}\text { Percentage } \\
\text { of total } \\
\text { number of } \\
\text { utterances }\end{array}$ \\
\hline Jana & $1 ; 3 ; 13^{3}$ & 277 & 7 & 270 & $19,69 \%$ \\
\hline Ashley & $1 ; 4 ; 7$ & 195 & 12 & 183 & $13,35 \%$ \\
\hline Mandie & $1 ; 3 ; 7$ & 121 & 3 & 118 & $8,61 \%$ \\
\hline Anke & $1 ; 0 ; 16$ & 116 & 8 & 108 & $7,88 \%$ \\
\hline Paul & $1 ; 5 ; 5$ & 115 & 9 & 106 & $7,73 \%$ \\
\hline Liandri & $1 ; 7 ; 11$ & 96 & 6 & 90 & $6,56 \%$ \\
\hline Wilma & $1 ; 0 ; 16$ & 83 & 0 & 83 & $6,05 \%$ \\
\hline Karel & $0 ; 10 ; 13$ & 81 & 1 & 80 & $5,84 \%$ \\
\hline Jacques & $1 ; 3 ; 1$ & 59 & 2 & 57 & $4,16 \%$ \\
\hline Anton & $0 ; 10 ; 11$ & 55 & 0 & 55 & $4,01 \%$ \\
\hline Henri & $1 ; 0 ; 25$ & 49 & 2 & 47 & $3,43 \%$ \\
\hline Marni & $1 ; 0 ; 11$ & 28 & 2 & 26 & $1,90 \%$ \\
\hline Francois & $1 ; 3 ; 17$ & 26 & 1 & 25 & $1,82 \%$ \\
\hline Lena & $0 ; 6 ; 21$ & 24 & 0 & 24 & $1,75 \%$ \\
\hline Marie & $0 ; 7 ; 2$ & 27 & 3 & 24 & $1,75 \%$ \\
\hline Annerie & $0 ; 11 ; 6$ & 24 & 1 & 23 & $1,68 \%$ \\
\hline Louise & $0 ; 8 ; 6$ & 22 & 1 & 21 & $1,53 \%$ \\
\hline Ronel & $0 ; 10 ; 24$ & 22 & 5 & 17 & $1,24 \%$ \\
\hline Eddie & $0 ; 10 ; 28$ & 8 & 0 & 8 & $0,58 \%$ \\
\hline Alicia & $0 ; 6 ; 17$ & 10 & 4 & 6 & $0,44 \%$ \\
\hline TOTAL & & $\mathbf{1 4 3 8}$ & $\mathbf{6 7}$ & $\mathbf{1 3 7 1}$ & $\mathbf{1 0 0 \%}$ \\
\hline
\end{tabular}

\footnotetext{
${ }^{3}$ This notation style refers to the child's age in years; months; days.
} 
The discrepancy of number of utterances between the children can mainly be allocated to the age differences. However, it was necessary to include children from a wide age range $(0 ; 6$ to $2 ; 0)$ in the study because of the fact that not all children start using their first lexical items at the same age (Fenson et al. 1994). This study specifically focuses on children's first lexical items, and therefore the aim was to capture data of children just starting to use recognisable language.

During the first phase of coding, the utterances were each coded inductively by the researcher according to the descriptions and examples of communicative intentions stated by Tomasello (2003: 37). The context of the utterance as provided by the parent was used to derive whether the child's communicative intention fitted into one of Tomasello's categories, and, if so, which one. During the second phase of coding, utterances were deductively identified that could not comfortably be divided into one of Tomasello's categories. Further notes were made regarding utterances that did fit into one of Tomasello's categories but required a more nuanced description of that category to include that utterance (e.g. the category to request/indicate the existence of objects to also include people and animals specifically). During the third phase of coding, the utterances that could not comfortably be fitted into one of the categories were grouped together, and it was identified that the communicative intention of all of these utterances was either to express an emotion/feeling or to respond to a conversation partner by means of imitation. These two communicative intentions were therefore identified in the Afrikaans data set in addition to Tomasello's categories, and will also be presented in the results section together with the other categories.

\section{Results}

Tomasello's (2003: 37) categories of communicative intentions were applied and compared to the Afrikaans-speaking children's first lexical items to determine whether these categories could also aptly describe the communicative intentions of Afrikaans-speaking children. All of the categories could be identified in the data set although some of the descriptions of the categories were adjusted to describe the various nuances of the Afrikaans utterances and intentions, and therefore include more samples from the Afrikaans data. These adjustments regarding the description of the Afrikaans data set will be discussed under each section of the categories further on. Table 2 presents a summary of all of Tomasello's communicative intentions, their frequency in the data, as well as Afrikaans examples of holophrases from the data. 
Table 2: Summary of communicative intentions

\begin{tabular}{|c|l|c|l|}
\hline \multicolumn{1}{|c|}{ Communicative intention } & $\begin{array}{l}\text { Frequency } \\
\text { (n=1371) }\end{array}$ & \multicolumn{1}{|c|}{ Examples } \\
\hline 1. & $\begin{array}{l}\text { Request/indicate the existence of } \\
\text { objects }\end{array}$ & 531 & $\begin{array}{l}\text { tone ('toes'); pappa ('daddy'); } \\
\text { pêperd ('horse') }\end{array}$ \\
\hline 2. & $\begin{array}{l}\text { Request/describe the recurrence of } \\
\text { objects/events }\end{array}$ & 11 & nog ('more'); hap ('bite') \\
\hline 3. & $\begin{array}{l}\text { Request/describe dynamic events } \\
\text { involving objects }\end{array}$ & 24 & toe ('closed'); apfel > afval ('fall') \\
\hline 4. & $\begin{array}{l}\text { Request/describe the actions of } \\
\text { people }\end{array}$ & 443 & $\begin{array}{l}\text { skop ('kick'); baf > blaas ('blow'); } \\
\text { y-tou }>\text { uittel ('take out'), }\end{array}$ \\
\hline 5. & $\begin{array}{l}\text { Comment on the location of } \\
\text { objects/people }\end{array}$ & 39 & $\begin{array}{l}\text { byte }>\text { buite ('outside'), } \\
\text { daa > daar ('there') }\end{array}$ \\
\hline 6. & $\begin{array}{l}\text { Ask basic questions } \\
\text { mamma? ('mommy?'); } \\
\text { waddie? > wat is die? ('what is this?') }\end{array}$ \\
\hline 7. & $\begin{array}{l}\text { Attribute a property to an object } \\
\text { mooi ('pretty'); war > warm ('hot'); } \\
\text { vieg > vlieg ('fly') }\end{array}$ \\
\hline 8. & $\begin{array}{l}\text { Use of performatives to indicate } \\
\text { specific social events and situations }\end{array}$ & 88 & $\begin{array}{l}\text { tatta ('bye-bye'); } \\
\text { awao > hallo ('hello') }\end{array}$ \\
\hline
\end{tabular}

The number of utterances that were grouped into one of Tomasello's categories amounts to 1275 . This is because the remaining utterances were grouped into two other categories of communicative intentions, namely expressing an emotion/feeling and responding to a conversation partner by means of imitation. After being compared with Tomasello's communicative intentions, the data set indicated that the Afrikaans-speaking children also used a number of utterances for these two communicative intentions. This will be discussed in detail in subsections 5.9.1 and 5.9.2.

\section{$5.1 \quad$ Request/indicate the existence of objects}

The first communicative intention on Tomasello's list is requesting/indicating the existence of objects. This intention occurs most frequently (531 times). According to Tomasello (2003: 37), this type of holophrase is used to request the name of an object by using a requesting intonation or to name an object through a neutral intonation. Eighteen children used utterances with this communicative intention, and the data indicated that all the children also referred to either people and/or animals, not just to objects. Since children's vocabulary is constantly expanding during this phase, it is not surprising that this intention, through which contact with objects, people, and animals in the child's environment are expressed, is so common. Examples ${ }^{4}$ of holophrases where the child refers to the existence of objects/people/animals, are given in examples (1) to (5).

\footnotetext{
${ }^{4}$ In each example structure, the following are given: (i) the pseudonym of the child who used the lexical item, (ii) the lexical item in Afrikaans as used by the child, (iii) the translation of the conventional form of the lexical item in brackets, and (iv) the context in which this lexical item was used as provided by the respondent. In cases where the lexical item as used by the child is not the conventional form, the conventional form in Afrikaans is also provided.
} 
(1)

$$
\begin{array}{lll}
\text { (1) Karel } & \text { /tone/ }{ }^{5} \text { ('toes') } & \text { Touches his toes on his own and says 'tone" ('toes'). } \\
\text { (2) Wilma } & \begin{array}{l}
\text { /pât-pât/>perd- } \\
\text { perd ('horse-horse') }
\end{array} & \text { When she sees her toy horse. }
\end{array}
$$

In Karel and Wilma's examples, it is clear that these lexical items are used to name something - a body part or a toy.

\section{(3) Mandie /pê/>perd ('horse')}

When she sees horses.

When she sees cattle.

In Mandie's example, the lexical item /pê/ (a clipping of the Afrikaans for 'horse') is used to refer to both horses and cattle. This holophrase is therefore used to refer to two different concepts although these two concepts are perceptually similar and thus it makes sense for Mandie to also use /pê/ ('horse') to refer to cattle. As her vocabulary and understanding of concepts expand, she will realise that a horse and a cow are not the same concept and should be named by two different lexical items.

(4) Alicia Ipappa/ ('daddy') When she sees her daddy.

In the example in (4), where Alicia calls her father /pappa/ ('daddy') when she sees him, it is clear that this type of holophrase can also name people and animals (as seen in example (3)), not just objects.

(5) Ashley /ta/ ('ta') When she wants to know something's name.

In example (5), Ashley uses the lexical item /ta/ ('ta') when she requests the name of an object. Although the lexical item "ta" is often used by adults when requesting a child to hand them something such as an object, it is not a conventionalised form in Afrikaans. In this case, the physical context in which the utterance takes place is therefore important to derive what Ashley means by using this lexical item and which object's name she is requesting.

\subsection{Request/describe the recurrence of objects/events}

The second communicative intention under discussion is the use of a lexical item to request/describe the recurrence of objects/events. According to Tomasello (2003: 37), this type of communicative intention is typically expressed by holophrases such as more and again. In the Afrikaans data, this intention is mainly expressed by the lexical item /nog/ ('more') or a form thereof, and this therefore corresponds with Tomasello's observation. This intention was coded 11 times, thus not occurring frequently in the data. Six children conveyed this communicative intention with an utterance they made. Examples (6) to (9) refer to lexical items where the recurrence of objects or events are requested or described.

$$
\text { Ashley } / n \hat{o} />\operatorname{nog}(\text { 'more') }
$$

When she wants to play some more.

$$
\text { Paul Inog/ ('more') }
$$

Asks for more cookies.

\footnotetext{
${ }^{5}$ The lexical items are given between forward slashes $(/)$ as an indication that this is how the child used it. In some cases, the lexical item is the conventional form, but in other cases it is not yet the conventional form, and the conventional form is then also provided.
} 
In Ashley's example in (6), an action is requested by the use of /nô/ which is indicated by her parent as a clipping of the Afrikaans word for more. In Paul's example in (7), the word /nog/ ('more') is used to request some more cookies, in other words to request an object. In examples (8) and (9), two verbs are used to fulfil this communicative intention.

(8) Wilma /hap/ ('bite')

When she wants to take another bite of the food.

(9) Anton /baai/>swaai ('swing') If he wants to swing some more.

In these two examples, an object or action is requested by using a lexical item that is not typically associated with this communicative intention. In Wilma and Anton's cases, the lexical items that indicate the specific action, namely /hap/ ('bite') and /baai/ ('swing'), are chosen to request the repetition of the action. According to Tomasello (2003: 38), children acquiring English as a first language rather choose the so-called "relational words" as holophrases for this type of communicative intention, such as more, gone, up, down, and off. But in these examples of Afrikaans first language acquisition, the children rather choose the verb from the adult's utterance to indicate the specific action. This connects to the salience of certain words in adult speech. In these two cases, one might assume that the adults placed more emphasis on the verbs in the utterance, this possibly being a reason why the children chose these specific words as holophrases.

\subsection{Request/describe dynamic events involving objects}

With regard to the third communicative intention, namely to request/describe dynamic events involving objects, Tomasello (2003: 37) states that this intention is mainly embodied through lexical items such as on, off, in, out, open, close, etc. Although not clearly stated, it is suggested that this communicative intention only involves non-living objects. Twenty-four cases of requesting/describing dynamic events involving objects were coded, and these utterances were made by 10 children. A variety of lexical items are used to fulfil this communicative intention holophrastically, as can be seen in examples (10), (11), and (12), and not just your "typical" lexical items as Tomasello suggests.

$$
\begin{array}{lll}
\text { Anke } & \text { lapfel/ > afval ('fall') } & \text { When something is falling. } \\
\text { Anton } & \text { /daai/ > draai ('turn') } & \text { When his toy is turning around in circles. } \\
\text { Jana } & \text { /ptre/ > buite ('outside') } & \text { When it is raining. }
\end{array}
$$

It is clear that Anke is trying to say the word afval ('falling') and Anton draai ('turn'). According to the respondent, Jana's lexical item refers to rain/outside.

In the following two examples, the lexical item /toe/ ('closed') is used to refer to the situation.
(13) Jana Itoe/ ('closed')
When something is closed.
(14) Francois /toe/ ('closed')
Anything that he cannot open, that is turned off, or is out of his reach.

The data set indicated that holophrases such as versions or clippings of the Afrikaans word klaar ('finished') are often used to describe a completed process, as can be seen in the following two examples. 
Lena $\quad \mid$ klaaa $/>$ klaar ('finished')

(16)

Ashley

$\mid$ tla $\mid>$ klaar

When she is finished with something, or something is used up, e.g. finished eating.

('finished')

\subsection{Request/describe the actions of people}

The fourth communicative intention on Tomasello's list is to request/describe the actions of people. This intention is mainly embodied through verbs such as eat, kick, ride, draw, etc. (Tomasello 2003: 37). However, this was not always the case in the Afrikaans data set. In most cases, the noun is used rather than the verb to indicate the action, and the context of use plays a big part in being able to derive what the child means with the lexical item. This also emphasises the fact that one cannot solely rely on the part of speech of the lexical item to derive the meaning of the holophrase.

In the Afrikaans data set, 7 of the 19 children that used an utterance with this communicative intention did not only refer to the actions of people but also to the actions of animals. Contexts in which the child describes his/her own actions are also very common in this category. This intention was coded 443 times in the data, making it the second most frequent communicative intention. Examples (17) to (21) can be seen as the description of the actions of people.

Karel /leukel/ > sleutel ('key') Says it when one is opening the door with a key.

In this example, Karel uses the lexical item /leukel/ ('key') when someone opens the door with a key. This lexical item, which is used as a noun in adult language, is being used here to refer to an action, and a possible syntactic construction of this holophrase could be Mommy uses the key to open the door. In examples (18) and (19), nouns are also used as holophrases to express an action.

$$
\begin{array}{lll}
\text { Anke Itande/ ('teeth') } & \text { When we are brushing our teeth. } \\
\text { Ashley } / \text { hys } />\text { huis ('home') } & \text { When we drive away from the school. }
\end{array}
$$

Ashley is probably trying to utter a whole phrase such as We are going home but is only able to utter the lexical item for home. In the following two examples, verbs are used as holophrases to indicate the action, and Mandie's use of /skop/ ('kick') correlates with Tomasello's example of this category.
Wilma $\quad$ baf/> blaas ('blow')
Mandie /skop/ ('kick')
When she is blowing her food that is too hot or when she blows out a birthday candle.
When she is kicking a ball.

In the following examples, the actions of animals, especially dogs, are requested or commented on.

$$
\begin{array}{lll}
\text { Anke } & \text { /doedoe/ ('sleep-sleep') } & \text { Points at the dog that is lying down. } \\
\text { Mandie } & \text { /byt/ ('bite') } & \text { Points at dog and says "byt" ('bite'). } \\
\text { Wilma } & \text { /uit/ ('out') } & \text { Says it to dogs when she sees them. }
\end{array}
$$


It also becomes clear that the children often request actions from people in order for one of their needs to be fulfilled. This action often has to be performed by a specific person or by anybody who is present in the communicative situation. See (25) to (29) as examples hereof.

\begin{tabular}{|c|c|c|c|}
\hline$(25)$ & Wilma & /toen/ > skoen ('shoe') & $\begin{array}{l}\text { If she wants one of the family members to put on } \\
\text { their shoes or if she wants to put on her own shoes. }\end{array}$ \\
\hline$(26)$ & Ashley & /padda/ ('frog') & $\begin{array}{l}\text { When she wants to sing a specific song, } \\
\text { "Paddatjie, wat maak jy daar?" ('Froggy, what } \\
\text { are you doing there?'). }\end{array}$ \\
\hline$(27)$ & Jacques & /water/ ('water') & When he is thirsty. \\
\hline$(28)$ & Anton & /myne/ ('mine') & When he wants something. \\
\hline (29) & Henri & $\begin{array}{l}\mid y \text {-tou/ > uittel ('take } \\
\text { out') }\end{array}$ & When he is in his cot and he wants to be taken out. \\
\hline
\end{tabular}

To express certain needs is an important part of young children's everyday lives because they cannot yet do much for themselves. It is therefore not surprising that in so many cases they intend to get someone to do something for them. For this intention, a variety of parts of speech is used, such as prepositions (Afrikaans words for off, out, on, etc.), pronouns (Afrikaans words for mine), nouns (Afrikaans words for mommy, bath, ball, etc.), and verbs (Afrikaans words for taste, play, look, etc.).

\subsection{Comment on the location of objects/people}

The fifth communicative intention that will be discussed is when children comment on the location of people or objects. With regard to this intention, the Afrikaans data largely correspond with Tomasello's examples of holophrases such as here, in, and out. Other lexical items used as holophrases are various forms of there ("daar"), gone ("weg"), and that one ("daai"), and then nouns such as bed ("bed") which indicates that it is the place where the action of sleeping takes place. Eleven children made utterances with this intention, and three of the children also commented on the location of animals, such as Mandie using the lexical item lweg/ ('gone') when the dog is not where he was a moment ago. This intention did not occur frequently, and was only identified for 39 utterances. See examples (30), (31), and (32) for holophrases where the children comment on the location of objects, people, or animals.

$\begin{array}{ll}\text { Anke } & \begin{array}{l}\text { /byte/ > buite } \\ \text { ('outside') }\end{array} \\ \text { Annerie } & \text { /weg/ ('gone') } \\ \text { Karel } & \begin{array}{l}\text { /belle/ > oorbelle } \\ \text { ('earrings') }\end{array}\end{array}$

When she is looking outside through the window.

When someone walks out of the room, they are gone.

Touches my ears and says "belle" ('earrings') when I do not wear my earrings.

In example (32), where Karel is using the lexical item /belle/ (clipping of oorbelle 'earrings') while touching his mother's ears, one might assume that he is trying to say that this is the place where his mother's earrings normally are, or it can possibly indicate a question of Where are mommy's earrings? In this case, the intonation with which Karel utters this lexical item will indicate precisely what his intention with uttering this lexical item is. This also connects with the next category, namely to ask basic questions. 


\subsection{Ask basic questions}

The sixth intention is to ask basic questions. Eleven children conveyed this intention in an utterance, and 10 of them also answered basic questions set to them by their conversation partner. The answering of questions was therefore also included in this intention. The children made 43 utterances with this communicative intention, and this type of utterance is therefore still limited at this early stage. According to Pine and Lieven (1993) and Tomasello (2003), the holophrases used for this intention can be so-called "frozen phrases", such as where's-it? or what-this?, which are "unparsed adult expressions" that function as holophrases. These frozen phrases involve another type of syntactic process to eventually withdraw the productive linguistic elements that can be used in other utterances and linguistic contexts in future. Tomasello (2003: 38) elaborates on this as follows:

For this the child must engage in a process of segmentation, with regard not only to the speech stream, but also to the communicative intentions involved so as to determine which components of the speech stream go with which components of the underlying communicative intention.

Tomasello (2003: 39) further explains that the "segmenting of (communicative) intentions is used by English-speaking children to learn some kinds of linguistic elements (for example, extracting unstressed prepositions such as of from such phrases as piece-of-ice and scared-ofthat". The next two cases, (33) and (34), are similar to Tomasello's examples of frozen phrases:

\section{Francois}

/het-jy-bal?/ ('you-have-ball?')

(34) Liandri /wa's-hy-nou?/ ('where's-he-now?')
Asked to any person, in the shop, where we are walking, etc.

For anything that was just here but is gone now, she asks where it is now? They were just here then.

In example (35), Jana only uses one word to represent the question of where her mother is, and in example (36) the three Afrikaans words "wat is die?" ('what is this?') are contracted and only pronounced as a one-word utterance "waddie?" which can roughly be translated as 'wha-this?'.

(35) Jana Imamma?/ ('mommy?') When she does not see me.

(36) Paul /waddie?/>wat-is-die? Points at pictures and asks what it is. ('what-is-this?')

In addition to asking basic questions, some of the Afrikaans children also communicatively intended to answer a question set by another person. This also naturally involves social interactions with other people. In examples (37) to (39), the children answer a question that is asked to them.

(37) Francois /hierso/ ('here') Answer to the question: "Francois where are you?"

(38) Ashley $\quad \mid K j a />$ Klara When I ask her what our dog, Klara's, name is.

('Klara')

(39) Karel /hoed/ ('hat')

Says it and touches his head when I ask where one's hat comes. 
As can be seen from the examples, the answers to the questions are very basic, but they are still regarded as holophrases because a single lexical item represents a possibly more "complete" answer that can be given to a question. In some cases, as in Karel's use of /hoed/ ('hat'), the child knows what the "right" answer to the question is (i.e. that the hat should come on the head), but he possibly does not yet know the lexical item for head, and therefore echoes his mother's use of /hoed/ ('hat').

\subsection{Attribute a property to an object}

Of the seventh intention, namely to attribute a property to an object, 96 utterances made by 14 of the children were indicated in the data. Of the 14 children, nine also attributed properties to people, and two of them attributed properties to animals. These examples were therefore included in this category. Tomasello (2003: 37) states that this intention is mainly embodied through adjectives. In the Afrikaans data, this is also mainly the case (see examples (40) and (41)), but there are also a few exceptions, as can be seen in examples (42) and (43).

\begin{tabular}{|c|c|c|c|}
\hline$(40)$ & Liandri & /mooi/ ('pretty') & $\begin{array}{l}\text { Looks at herself in the mirror and says "mooi" } \\
\text { ("pretty') when I comb her hair. }\end{array}$ \\
\hline$(41)$ & Anke & Iná/> nat ('wet') & $\begin{array}{l}\text { Touches water or a wet cloth and says "ná" } \\
\text { ('wet'). }\end{array}$ \\
\hline$(42)$ & Jana & $\mid n y />\operatorname{sny}($ 'cut') & When she sees a knife. \\
\hline (43) & Paul & $\begin{array}{l}\text { /vieg/ > vlieg } \\
\text { ('fly') }\end{array}$ & Points at a bird. \\
\hline
\end{tabular}

In examples (42) and (43), a verb is used as a holophrase to attribute a certain property to an object/animal, more specifically that a knife can cut and that a bird can fly. These two examples were not included in the intention request/describe dynamic events involving objects because Jana and Paul use these lexical items only when they see the object, not when the object is involved in a dynamic event such as cutting or flying. One can therefore assume that Jana and Paul refer to the various properties, i.e. that a knife has the property to cut and a bird has the property to fly. Another possibility is that they are referring to an event that already took place and are now commenting on it.

The data set also indicated that holophrases in this category are often used to indicate that something belongs to someone, therefore attributing the property of being owned by someone to an object. In some cases, these holophrases also connect with requesting an action from an actor because of the lexical item /myne/ ('mine') which is sometimes used by a child to demand an object that somebody took from them. But the important difference is that no direct action is demanded with this communicative intention, as can be seen in examples (44) and (45).

$\begin{array}{lll}\text { (44) Liandri } & \text { Imyne/ ('mine') } & \begin{array}{l}\text { Grabs something and says "myne" ('mine') if } \\ \text { she does not want anybody to take it from her. }\end{array} \\ \text { (45) Jana } & \begin{array}{l}\text { Imammal } \\ \text { ('mommy') }\end{array} & \begin{array}{l}\text { Started at } 17 \text { months to use this as a form of } \\ \text { possession, e.g. when she points at something } \\ \text { of mine, like my clothes, my chair, my cup. }\end{array}\end{array}$


Example 45 is an indication that it is important to always take the context of use into account to determine the meaning of the lexical item, or the intention the child has with it, because Imamma/ ('mommy') is not used here for conventional reasons.

\subsection{Use of performatives to indicate specific social events and situations}

The eighth communicative intention as provided by Tomasello (2003: 37) is the use of performatives to indicate specific social events and situations. A performative is when the uttering of the utterance is the act itself, as in the cases of hello, goodbye, thank you, and no. These utterances are not used to describe a situation or to request something, but rather to function socially with people. This intention was coded 88 times, and conveyed in utterances by 15 children. This presumes that social interaction with other people also forms part of a young child's environment and activities although it is not as frequent yet. See examples (46) to (48) where performatives are used to express social events.
Louise
Itatta/ ('bye-bye')
Waves and says it when she greets someone.
(47) Jana
lawao/ > hallo
When she sees someone walking by. ('hello')
(48) Marni
|ankie/ > dankie ('thank you')
She said "ankie" ('thank you') when I gave her a bottle with juice.

\subsection{Two other communicative intentions identified in the Afrikaans data set}

As already mentioned, two other communicative intentions that do not appear on Tomasello's list were identified in the Afrikaans data set. The first is the intention of expressing an emotion/feeling, and the second is the intention of responding to a conversation partner but only succeeding in imitating the partner's words. Thirty-nine utterances made by 12 of the children with the intention of expressing an emotion/feeling were identified in the data, and 58 utterances by 14 of the children with the intention of responding to a conversation partner by means of imitating their words. These frequencies are not high but nevertheless cannot be ignored as it could be identified and grouped together in the data. Furthermore, it was not only one or two children who made utterances of this kind but more than half of the research group. These two intentions are discussed in 5.9.1 and 5.9.2.

\subsubsection{Expressing an emotion/feeling}

This intention connects to the description of the actions of people and expressing a need. However, in this case, there is not necessarily a visible action taking place. With the use of this holophrase, the child intends to share how s/he is feeling, whether it be an emotion such as happiness or sadness, or a feeling of satisfaction, tiredness or pain. According to Cole and Cole (2001: 300), infants' cries and coos are known to express their emotional states from birth onwards. Around $0 ; 11$ to $1 ; 0$, they start to realise that they can make sound sequences that can anticipate, guide, and stimulate their own and others' actions and feelings. Thus the children still want to express their emotions/feelings but can gradually start doing this with linguistic items and not only with cries and coos: "With the emergence of the capacity to use words, children acquire the ability to express themselves and organize their activity in a new way" (Cole and Cole 2001: 300). There are 39 identified examples of this intention in the data, and the examples in (49) to (51) were chosen as representatives of this category. 


$\begin{array}{llll}\text { (49) Jana } & \text { /einal ('ouch') } & \text { When she is unhappy about something. } \\ \text { (50) Ashley } & \begin{array}{l}\text { /dassy/ }>\text { daarsy } \\ \text { ('there you go') }\end{array} & \begin{array}{l}\text { When she achieves something, like putting } \\ \text { blocks on each other or into a bowl. }\end{array} \\ \text { (51) Jacques } \quad \text { loulik/('cute') } & \begin{array}{l}\text { When he has done something of which he is } \\ \text { very proud. }\end{array}\end{array}$

Specifically referring to Ashley's use of /dassy/ ('there-you-go') to emphasise when she has achieved something, various forms or clippings of the phrase /daar's hy/ ('there you go') are commonly used holophrastically by the children to express a feeling of satisfaction or pride. Jana makes an interesting categorical connection between physical pain - usually expressed through the lexical item /eina/ ('ouch') - and emotional pain, such as being unhappy about something.

\subsubsection{Responding to a conversation partner by means of imitation}

Tomasello (2003: 31) states that the motivational bases for children's first utterances seem to emanate from "(1) a desire to communicate with other persons, and (2) a desire to be like other persons (that is, to imitate them)". Leonard et al. (1983: 591) propose that a function of imitation, apart from the facilitation of the acquisition of new lexical items, is to "increase the child's ability to serve as a conversation partner by providing him or her with a means for turn taking". In the cases where the child responds with an imitation of the word the adult has uttered, it can be assumed that one of the reasons the child is uttering this word is to be able to respond/communicate with his/her conversation partner although $\mathrm{s} /$ he cannot do so yet in a novel manner. This intention also connects to the usage-based notion of grammar that is built up through language usage which enables speakers to become proficient language users. The child has the intention of communicating with the other person but only succeeds in imitating that person's utterance or part of the utterance. This intention was identified 58 times in the data, and examples (52) to (54) can be seen as examples hereof.

$\begin{array}{lll}\text { (52) Paul } & \text { /doekie/ ('nappy') } & \begin{array}{l}\text { Says "doekie" ('nappy') with me when I } \\ \text { change his nappy. }\end{array} \\ \text { (53) Anke } \quad \begin{array}{l}\text { /wate/ }>\text { water } \\ \text { ('water') }\end{array} & \begin{array}{l}\text { When she drinks water and we say the word, } \\ \text { she repeats it. }\end{array} \\ \text { (54) Wilma /uit/ ('out') } & \text { Repeats the word after me when she hears it. }\end{array}$

\section{Discussion}

The research question for this study is to what extent Tomasello's usage-based categories of communicative intentions children from around the world have with their holophrases can also aptly describe the Afrikaans data set. All of Tomasello's categories could be identified in the Afrikaans data. The descriptions of some of the categories were, however, expanded to include the following: (i) request/indicate the existence of objects to also include people and animals, (ii) request/describe the actions of people to also include the actions of animals, (iii) comment on the location of objects/people to also include the location of animals, (iv) ask basic questions to also include the answering of basic questions, and (v) attribute a property to an object to also include attributing a property to a person or animal. 
In addition to Tomasello's categories, two types of communicative intentions that are not on Tomasello's list were identified in the Afrikaans data, namely to express an emotion/feeling and to respond to a conversation partner by means of imitation. The identification of these categories does not, however, imply that these communicative intentions are not also present in data sets from children acquiring other languages - a follow-up study on this could provide interesting results.

With regard to the first additional communicative intention, to express an emotion/feeling, Roben et al. (2013) conducted a study on how language skills help toddlers to regulate their emotions. The authors found that toddlers with better language skills, and those whose language skills increased more over time, appeared less angry at 48 months and that their anger declined more over time. This supports the finding that expressing emotions is part of young children's communicative needs, and that they can employ language to regulate their emotions. Other studies which have also investigated the development of linguistic expression of emotions in early lexical development are, amongst others, Fabes et al. (2001), Ridgeway et al. (1985), Smiley and Huttenlocher (1989), and Widen and Russell (2008). A more extensive study of Afrikaans-speaking children's development of expressing emotions linguistically can also contribute to this body of literature.

With regard to the second additional category, to respond to a conversation partner by means of imitation, some other studies have been conducted on how imitation aids language learning and development (e.g. Speidel and Nelson 1989, Meltzoff and Gopnik 2011). Leonard et al. (1983) tested three hypotheses regarding young children's imitation of lexical items. The two hypotheses tested and discussed by these authors is (i) that the facilitative effects of imitation aid lexical production, and (ii) that imitation of new words serves a conversational function by providing the child with a means of responding when $\mathrm{s} /$ he knows too little about the topic to respond in a novel manner (Leonard et al. 1983: 599). The authors found that lexical items referring to topics the children knew the least about were more likely to be imitated than commented on (Leonard et al. 1983: 600). This provides evidence for imitation also occurring as a result of the children intending to take part communicatively in the discourse.

The intention to request/describe the existence of objects occurred most frequently in the data. This indicates that children aged $0 ; 6$ to $2 ; 0$ are actively busy exploring and discovering their environments. This communicative intention also explicitly connects with the usage-based notion of common ground between the speaker and addressee that needs to be established within a joint attentional frame. These objects that the children are requesting or describing are usually physically present within the joint attentional frame, and therefore the children can design their utterances to be understood as intended (Clark 2015: 336).

This list of communicative intentions expressed by Afrikaans-speaking children with their first lexical items indicates that these children are learning to be skilled communicators from an early age. The usage-based notion of intention-reading within a joint attentional frame is especially relevant during the holophrastic phase as the meaning of their one-word utterances should be derived from the context of use and not from the "traditional" adult-like meaning of the utterance.

As their knowledge of language and lexical items develops by means of their use of the language, they will move on from holophrases and start to combine words syntactically to express more complicated communicative intentions. This also supports the bottom-up usagebased notion that children start out with more specific schemas that they gradually expand and generalise to more abstract schemas that will form part of the grammar of their language. 


\section{Conclusion}

The idea that the Afrikaans-speaking children in this study want to convey a number of communicative intentions with their holophrases corresponds with the usage-based approach to first language acquisition. Tomasello's usage-based categories of communicative intentions are also applicable to Afrikaans language data, although two other types of communicative intentions were identified in the data set, and some of the categories' descriptions were adjusted to include more samples from the data set. This list can possibly be refined and expanded even further by means of future research and cross-linguistic studies where the Afrikaans data are compared to other languages, as well as using larger data sets. Another possibility for research is a longitudinal study of how these Afrikaans holophrases, i.e. the more specific language examples, lead to more abstract schemas, i.e. more generic language examples.

\section{References}

Ambridge, B. and E. Lieven. 2015. A constructivist account of language acquisition. In B. MacWhinney and W. O'Grady (Eds.) The handbook of language emergence. West Sussex: Wiley Blackwell. pp. 478-509. https://doi.org/10.1002/9781118346136.ch22

Barrett, M.D. 1982. The holophrastic hypothesis: Conceptual and empirical issues. Cognition 11: 47-76. https://doi.org/10.1016/0010-0277(82)90004-x

Barrett, M.D. (Ed.) 1985. Children's single-word speech. Chichester, New York: John Wiley and Sons Ltd.

Bates, E. 1976. Language and context: The acquisition of pragmatics. New York, San Francisco, and London: Academic Press.

Behrens, H. 2009. Usage-based and emergentist approaches to language acquisition. Linguistics 47(2): 383-411. https://doi.org/10.1515/ling.2009.014

Brink, N. and A. Breed. 2017. Hoe jong Afrikaanssprekende kinders betekenis aan hul vroeë taalgebruik verbind ['The way in which young Afrikaans-speaking children connect meaning to their early vocabulary']. Journal of Humanities 57(4): 1012-1036. https://doi.org/10.17159/ 2224-7912/2017/v57n4a10

Cattell, R. 2000. Children's language: Consensus and controversy. London: Cassell.

Clark, E.V. 2001. Emergent categories in first language acquisition. In M. Bowerman and S.C. Levinson (Eds.) Language acquisition and conceptual development. Cambridge: Cambridge University Press. pp. 379-405. https://doi.org/10.1017/cbo9780511620669.015

Clark, E.V. 2003. First language acquisition. Cambridge: Cambridge University Press.

Clark, E.V. 2015. Common ground. In B. MacWhinney and W. O'Grady (Eds.) The handbook of language emergence. West Sussex: Wiley Blackwell. pp. 328-353. https://doi.org/10.1002/ 9781118346136.ch15 
Cole, M. and S.R. Cole. 2001. The development of children. New York: Worth Publishers.

Crystal, D. 2005. How language works. London: Penguin Books.

Dore, J. 1975. Holophrases, speech acts and language universals. Journal of Child Language 2(1): 21-40. https://doi.org/10.1017/s0305000900000878

Fabes, R.A., N. Eisenberg, L.D Hanish and T.L. Spinrad. 2001. Preschoolers' spontaneous emotion vocabulary: Relations to likability. Early Education and Development 12(1): 11-27. https://doi.org/10.1207/s15566935eed1201_2

Fannin, D.K., O.A. Barbarin and E.R. Crais. 2018. Communicative function use of preschoolers and mothers from differing racial and socioeconomic groups. Language, Speech and Hearing Services in Schools 49(2): 306-319. https://doi.org/10.1044/2017_lshss-17-0004

Fenson, L., P.S. Dale, J.S. Reznick, E. Bates, D.J. Thal and S.J. Pethick. 1994. Variability in early communicative development. Monographs of the Society for Research in Child Development 59(5): 1-190. https://doi.org/10.2307/1166093

Gândara, J.P. and D.M. Befi-Lopes. 2010. Trends on lexical acquisition in children within normal development and children with developmental language disorder. Revista da Sociedade Brasileira de Fonoaudiologia 15(2): 297-304. https://doi.org/10.1590/s1516-80342010000200024

Greenfield, P.M. and J.H. Smith. 1976. The structure of communication in early language development. New York, San Francisco, and London: Academic Press.

Halliday, M.A.K. 1975. Learning how to mean: Explorations in the development of language. London: Edward Arnold.

Hann, L.J., N.C. Brady, L. McCary, L. Rague and J.E. Roberts. 2017. Early social communication in infants with fragile $\mathrm{X}$ syndrome and infant siblings of children with autism spectrum disorder. Research in Developmental Disabilities 71: 169-180. https://doi.org/10. 1016/j.ridd.2017.10.004

Kemmer, S. and M. Barlow. 2000. Introduction: A usage-based conception of language. In M. Barlow and S. Kemmer (Eds.) Usage based models of language. Stanford: CSLI Publications. pp. vii-xxviii.

Lachlan Mackenzie, J. 1998. The basis of syntax in the holophrase. In M. Hannay and A.M. Bolkestein (Eds.) Functional grammar and verbal interaction. Amsterdam: John Benjamins. pp. 267-295. https://doi.org/10.1075/slcs.44.17mac

Leonard, L.B., K. Chapman, L.E. Rowan and A.L. Weiss. 1983. Three hypotheses concerning young children's imitations of lexical items. Developmental Psychology 19(4): 594-601. https://doi.org/10.1037/0012-1649.19.4.591

MacWhinney, B. 1975. Rules, rote, and analogy in morphological formations by Hungarian children. Journal of Child Language 2: 65-77. https://doi.org/10.1017/s0305000900000891 
MacWhinney, B. 1982. Basic syntactic processes. In S. Kuczaj (Ed.) Language development. Volume 1: Syntax and semantics. Hillsdale, NJ: Lawrence Erlbaum. pp. 73-136.

McDaniel, J., K. D'Ambrose Slaboch and P. Yoder. 2018. A meta-analysis of the association between vocalizations and expressive language in children with autism spectrum disorder. Research in Developmental Disabilities 72: 202-213. https://doi.org/10.1016/j.ridd.2017.11.010

McNeill, D. 1970. The acquisition of language: The study of developmental psycholinguistics. New York: Harper and Row.

Meltzoff, A.N. and A. Gopnik. 2011. On linking nonverbal imitation, representation, and language learning in the first two years of life. New York: Springer. https://doi.org/10.1007/ 978-1-4612-1011-5_2

Miller, S., M. Jungheim and M. Ptok. 2014. Erstspracherwerbsforschung und Spracherwerbstheorien ['First language acquisition research and theories of language acquisition']. HNO 62: 242-248. https://doi.org/10.1007/s00106-014-2855-z

Pan, B.A. 2012. Assessing vocabulary skills. In E. Hoff (Ed.) Research methods in child language. Sussex: Blackwell. pp. 240-251.

Peccei, J.S. 2006. Child language: A resource book for students. New York: Routledge.

Pine, J. and E. Lieven. 1993. Reanalysing rote-learned phrases: Individual differences in the transition to multi-word speech. Journal of Child Language 20: 551-571. https://doi.org/ $10.1017 / \mathrm{s} 0305000900008473$

Ridgeway, D., E. Waters and S.A. Kuczaj. 1985. Acquisition of emotion-descriptive language: Receptive and productive vocabulary norms for ages 18 months to 6 years. Developmental Psychology 21(5): 901-908. https://doi.org/10.1037/0012-1649.21.5.901

Roben, C.K.P., P.M. Cole and L.M. Armstrong. 2013. Longitudinal relations among language skills, anger expression, and regulatory strategies in early childhood. Child Development 84(3): 891-905. https://doi.org/10.1111/cdev.12027

Sandbank, M., T. Woynaroski, L. Watson, E. Gardner, B. Kaysili and P. Yoder. 2017. Predicting intentional communication in preverbal preschoolers with autism spectrum disorder. Journal of Autism and Developmental Disorders 47(6): 1581-1594. https://doi.org/10.1007/ s10803-017-3052-1

Small, M.Y. 1990. Cognitive development. San Diego: Harcourt Brace Jovanovich.

Smiley, P. and J. Huttenlocher. 1989. Young children's acquisition of emotion concepts. In C. Saarni and P.L. Harris (Eds.) Children's understanding of emotion. Cambridge: Cambridge University Press. pp. 27-49.

Speidel, G.E. and K.E. Nelson. (Eds.) 1989. The many faces of imitation in language learning. New York: Springer Science and Business Media. 
Tomasello, M. 2000. First steps toward a usage-based theory of language acquisition. Cognitive Linguistics 11(1/2): 61-82. https://doi.org/10.1515/cogl.2001.012

Tomasello, M. 2003. Constructing a language. Cambridge, MA: Harvard University Press.

Tomasello, M. and E. Bates. (Eds.) 2001. Language development: The essential readings. Oxford: Blackwell.

Turner, S. 2015. Tomasello's theory of first language acquisition. In J. Littlemore and J.R. Taylor (Eds.) The Bloomsbury companion to cognitive linguistics. London: Bloomsbury. pp. 91-102. https://doi.org/10.5040/9781472593689.ch-006

Widen, S.C. and J.A. Russell. 2008. Children acquire emotion categories gradually. Cognitive Development 23(2): 291-312. https://doi.org/10.1016/j.cogdev.2008.01.002

Windfuhr, K.L., B. Faragher and G. Conti-Ramsden. 2002. Lexical learning skills in young children with specific language impairment (SLI). International Journal of Language and Communication Disorders 37(4): 415-432. https://doi.org/10.1080/1368282021000007758 